\title{
Association between parental guilt and oral health problems in preschool children
}

\section{Thiago Saads Carvalho(a) Jenny Abanto(b) \\ Fausto Medeiros Mendes(b) Daniela Prócida Raggio(b) Marcelo Bönecker ${ }^{(b)}$}

(a) Department of Preventive, Restorative and Pediatric Dentistry, Univ of Bern, Bern, Switzerland.

(b) Departamento de Odontopediatria, Faculdade de Odontologia, Univ de São Paulo, São Paulo, SP, Brazil.
Declaration of Interests: The authors certify that they have no commercial or associative interest that represents a conflict of interest in connection with the manuscript.

Corresponding Author:

Thiago Saads Carvalho

E-mail: thiagosaads@hotmail.com

Submitted: May 14, 2012

Accepted for publication: Aug 11, 2012

Last revision: Aug 23, 2012

\begin{abstract}
Parents may feel guilty about their children's oral problems, which can affect their quality of life. The aim of this study was to assess the presence of parental guilt and its association with early childhood caries (ECC), traumatic dental injuries (TDI) and malocclusion (AMT) in preschool children. All 2 to 5 year-old children $(\mathrm{N}=305)$, and their parents, seeking dental care at the University of São Paulo Dental School one-week Screening Programme, were asked to participate in the study, and 260 agreed. Children were examined by two calibrated dentists, and their parents answered a socioeconomic and ECOHIS questionnaire; the question on guilt was used as the dependent variable. Regression analyses examined the association between parental guilt and ECC, TDI, AMT and socioeconomic factors. A total of $35.8 \%$ of parents felt guilty. This was only associated with caries severity. No association was found between guilt and TDI, AMT or socioeconomic factors. ECC was present in $63.8 \%$ of the children; the mean $( \pm \mathrm{sd}) \mathrm{dmf}-\mathrm{t}$ score was $7.29( \pm 2.78)$. Thus, the number of parents feeling guilty increases with the increase of their children's dental caries severity. Parental guilt is related to caries but is not associated with TDI or AMT.
\end{abstract}

Descriptors: Guilt; Dental Caries; Tooth Injuries; Malocclusion; Quality of Life.

\section{Introduction}

Early childhood caries (ECC) is a disease involving at least one decayed, missing or filled tooth (dmf-t $\geq 1)$ in children no older than 71 months. ${ }^{1}$ ECC has been associated with children's diet and socioeconomic background, and although its incidence is decreasing, it is still common among preschool children. ${ }^{2}$ Traumatic dental injuries (TDI) are also frequent in preschool children and are becoming a public health problem. ${ }^{3}$ The prevalence of TDI has been associated with the child's age and the presence of malocclusion. ${ }^{4,5}$ The latter factor is an anomaly usually caused by deleterious oral habits. In preschool children, the prevalence of malocclusion can be as high as $76 \%$ and is most frequent in the anterior teeth (Anterior Malocclusion Traits - AMT). ${ }^{6,7}$

It is believed that the above-mentioned conditions can be prevented, particularly when the children's parents and caregivers have access to information about how their children's oral health is their responsibility. ${ }^{8-10}$ If parental knowledge about oral health is increased, there is a possibility 
that they will not feel guilty about their children's oral problems. ${ }^{11}$ However, to the best of our knowledge, this is the first study to assess whether parents feel guilty about the presence of ECC, TDI or AMT in their children. ${ }^{11}$ Moreover, socioeconomic factors should be investigated, as they are strong predictors of the prevalence of oral disease in children. ${ }^{12}$ Hence, further studies on the subject are still considered necessary.

Accordingly, the aim of this study was to examine preschool children for the presence of ECC, TDI and AMT and to investigate possible association of these variables with parental guilt as well as socioeconomic factors.

\section{Methodology}

This study was reviewed and approved by the Research Ethics Committee, School of Dentistry, USP (36/2009); all participants gave informed consent to participate in the study.

\section{Participants}

All preschool children, aged 2 to 5 years, and their parents, who sought dental care during the Screening Program, were invited to participate in this study $(\mathrm{N}=305)$. Children must not have been undergoing dental and orthodontic treatment. The children's age was categorised as: $2<3 ; 3<4 ; 4<5$; $5<6$, and labelled as: 2 years old (yo), 3 yo, 4 yo and 5 yo, respectively. The children could be of any gender, and their parents must have agreed to participate in the study.

A total of 260 parents and children agreed to participate in the study (response rate of $85.2 \%$ ). Participation in this study was not a sine qua non condition to be treated at the dental clinic. Therefore, all non-participants were still enrolled for treatment at the clinic.

Two calibrated paediatric dentists examined the children while the children's parents answered questionnaires, in an interview format, on the socioeconomic conditions of the family and about whether they felt guilty about their children's oral problems.

\section{Children's oral examination}

The examinations for ECC, TDI and AMT were performed in a dental unit using an operating light, a 3 -in-1 syringe, tongue depressors and WHO periodontal probes.

Before the study, intra-examiner agreements were calculated one week apart using primary teeth, pictures or model casts for ECC, TDI and AMT; kappa values were all $>0.8$. For inter-examiner reliability, both examiners assessed $26(10 \%)$ children, giving Cohen's kappa values of $0.8,0.9$ and 1.0 for ECC, TDI and AMT, respectively.

ECC was assessed according to the dmf-t World Health Organization (WHO) criteria ${ }^{13}$ and categorised according to severity: ${ }^{1,14}$

- dmf-t $0=$ caries-free;

- dmf-t 1-5 = low severity; or

- $\mathrm{dmf}-\mathrm{t} \geq 6$ = high severity.

The types of TDI were classified according to the system adopted by the WHO. ${ }^{15}$ As the upper front teeth are more prone to any type of traumatic dental injury, ${ }^{5,16}$ the present study assessed TDI from the upper canine to the opposite upper canine. Injuries to the hard dental tissues, the pulp and the alveolar process as well as injuries to the periodontal tissues were assessed. This variable was analysed according to the presence or absence (tooth present and sound) of TDI.

Anterior Malocclusion Traits (AMT) included anterior open bite, overjet greater than or equal to $4 \mathrm{~mm}$ and anterior cross bite. Children were categorised as either having, or not, AMT. ${ }^{17}$

\section{Socioeconomic questionnaire and parental guilt}

Two interviewers, who were blinded to the oral examinations, were trained in the reading and intonation of the questions from the questionnaire. They conducted the interviews with a questionnaire on the family socioeconomic conditions ${ }^{18}$ and the ECOHIS questionnaire for Oral Health Impact on the Quality of Life of preschool children. This study focused on one of the questions from the family section of the questionnaire that showed a good internal consistency and test-retest reliability. ${ }^{19}$ The parent was asked how often he/she, or any other family member, felt guilty because of their child's dental 
problems. This question had the following response options:

- never,

- hardly ever,

- occasionally,

- often and

- very often.

To analyse the data, the answers about parental guilt were changed to a dichotomous binomial variable-either the absence (including only the "never" response option) or the presence of guilt (including the remaining response options).

\section{Data analysis}

The question on feeling guilty was taken from the ECOHIS questionnaire, and the answer to this question was used as dependent variable. Forward stepwise Poisson regression analysis with robust variance was performed to observe the association between parental guilt (outcome) with each oral problem (ECC, TDI, AMT) and with each socioeconomic factor. Additionally, the oral problems (ECC, TDI and AMT) were considered as outcomes and were tested for association with the socioeconomic factors. Covariates with $\mathrm{p}<0.20$ on the univariate analysis were considered for each of the final models. The order of including the variables in the multivariate regression model was based on biological plausibility. Variables with $\mathrm{p}<0.05$ were kept in the multivariate model. The Poisson regression analysis should be interpreted using the Rate Ratio (RR) score. If RR is less than 1 , the analysed variable decreases the possibility that the outcome will occur. If RR is greater than 1 , the analysed variable increases the possibility that the outcome will occur. The outcome event was either parental guilt or ECC, and the individual subject (child) was considered as a unit of analysis. Spearman correlation was performed between ECC and parental guilt; the statistical software used was STATA 8.0 (Stata Corp., College Station, USA).

\section{Results}

The general characteristics of the children and their socioeconomic status are expressed in Tables
1 and 2 . ECC was present in $63.8 \%$ of the children, and the mean $( \pm$ sd) dmf-t score was $7.3( \pm 2.8)$. TDI and AMT were present in $30.0 \%$ and $24.2 \%$ of the children, respectively.

Parental guilt was correlated to dental caries (coefficient of $0.333, \mathrm{p}<0.001)$; a total of $35.8 \%$ of the

Table 1 - Univariate analyses of the association between parental guilt, oral conditions and socioeconomic factors. (continued on next page)

\begin{tabular}{|c|c|c|c|}
\hline $\begin{array}{l}\text { Oral and Socio- } \\
\text { economic conditions }\end{array}$ & n (\%) & $\begin{array}{c}\text { Robust RR } \\
(95 \% \mathrm{Cl})\end{array}$ & P value* \\
\hline \multicolumn{4}{|c|}{ ECC } \\
\hline No caries & $94(36.2)$ & & \\
\hline 1 to 5 teeth affected & $87(33.4)$ & $1.90(1.13-3.20)$ & \\
\hline $\begin{array}{c}6 \text { or more teeth } \\
\text { affected }\end{array}$ & $79(30.4)$ & $3.57(2.23-5.72)$ & $<0.001$ \\
\hline \multicolumn{4}{|c|}{ TDI } \\
\hline No & $182(70.0)$ & & \\
\hline Yes & $78(30.0)$ & $0.99(0.68-1.43)$ & 0.950 \\
\hline \multicolumn{4}{|c|}{ AMT } \\
\hline No & $197(75.8)$ & & \\
\hline Yes & $63(24.2)$ & $0.95(0.72-1.26)$ & 0.727 \\
\hline \multicolumn{4}{|c|}{ Child's sex } \\
\hline Male & $137(52.7)$ & & \\
\hline Female & $123(47.3)$ & $1.01(0.71-1.43)$ & 0.962 \\
\hline \multicolumn{4}{|c|}{ Child's age } \\
\hline 2 years old & $46(17.7)$ & & \\
\hline 3 years old & $60(23.1)$ & $1.44(0.78-1.65)$ & \\
\hline 4 years old & $66(25.4)$ & $1.76(1.00-3.12)$ & \\
\hline 5 years old & $88(33.8)$ & $1.13(0.62-2.04)$ & 0.107 \\
\hline \multicolumn{4}{|c|}{ Marital status of the parents } \\
\hline Married parents & $185(71.2)$ & & \\
\hline Separated parents & $75(28.8)$ & $1.00(0.68-1.48)$ & 0.984 \\
\hline \multicolumn{4}{|c|}{ Household crowding } \\
\hline No crowding & $65(25.2)$ & & \\
\hline $\begin{array}{l}1 \text { inhabitant } \\
\text { per room }\end{array}$ & $78(30.2)$ & $1.36(0.82-2.24)$ & \\
\hline $\begin{array}{l}2 \text { inhabitants } \\
\text { per room }\end{array}$ & $51(19.8)$ & $1.41(0.83-2.42)$ & \\
\hline $\begin{array}{l}3 \text { inhabitants } \\
\text { per room }\end{array}$ & $64(24.8)$ & $1.55(0.94-2.54)$ & 0.380 \\
\hline \multicolumn{4}{|c|}{ House property } \\
\hline No & $80(30.8)$ & & \\
\hline Yes & $180(69.2)$ & $0.79(0.55-1.13)$ & 0.201 \\
\hline
\end{tabular}


Table 1 (continued)

\begin{tabular}{|c|c|c|c|}
\hline \multicolumn{4}{|c|}{ Mother's age } \\
\hline$\leq 30$ years & $121(46.7)$ & & \\
\hline$>30$ years & $138(53.3)$ & $0.74(0.53-1.05)$ & 0.093 \\
\hline \multicolumn{4}{|c|}{ Father's age } \\
\hline$\leq 30$ years & $156(66.7)$ & & \\
\hline$>30$ years & $78(33.3)$ & $1.20(0.79-1.84)$ & 0.395 \\
\hline \multicolumn{4}{|c|}{ Number of siblings } \\
\hline None & 85 (32.9) & & \\
\hline 1 & $87(33.7)$ & $1.32(0.88-1.97)$ & \\
\hline 2 or more & $86(33.3)$ & $0.78(0.49-1.26)$ & 0.051 \\
\hline \multicolumn{4}{|c|}{ Mother's education } \\
\hline$<8$ years & $102(39.7)$ & & \\
\hline$\geq 8$ years & $155(60.3)$ & $0.81(0.57-1.15)$ & 0.242 \\
\hline \multicolumn{4}{|c|}{ Father's education } \\
\hline$<8$ years & $123(52.6)$ & & \\
\hline$\geq 8$ years & $111(47.4)$ & $0.88(0.61-1.28)$ & 0.502 \\
\hline \multicolumn{4}{|c|}{ Mother works away from home } \\
\hline No & $120(46.5)$ & & \\
\hline Yes & $138(53.5)$ & $0.81(0.58-1.15)$ & 0.243 \\
\hline \multicolumn{4}{|c|}{ Father works away from home } \\
\hline No & $39(16.7)$ & & \\
\hline Yes & $194(83.3)$ & $1.25(0.67-2.34)$ & 0.487 \\
\hline Family Income & $247(95.0)$ & $1.00(1.00-1.00)$ & 0.101 \\
\hline
\end{tabular}

* calculated by Wald test. Robust RR: Robust Rate Ratio. parents felt guilty. Table 1 shows that, as the severity of caries increases in children, more parents feel guilty ( $\mathrm{p}<0.001)$. On the other hand, no association was found with any of the socioeconomic factors or with TDI or AMT ( $p>0.05$ ). The forward stepwise multivariate model showed that only ECC was significantly related to parental guilt; therefore, the table is not shown.

As the "multivariate" model for parental guilt only included ECC, Table 2 was constructed to show the distribution of guilt in relation to the children's age and caries severity.

To better understand the sample, a multivariate model was developed by considering the severity of caries as an outcome (Table 3 ).

In this sample, TDI was not associated with the socioeconomic conditions ( $p>0.05)$, but was associated with AMT $(\mathrm{p}<0.001)$. Similarly, no association was observed between AMT and any of the analysed socioeconomic factors $(\mathrm{p}>0.05)$.

\section{Discussion}

The present study found that parents feel guilty when their children's caries severity increases. To the best of our knowledge, only one study, to date, has focused on the presence of parental guilt in relation to oral diseases. ${ }^{11}$ In that study, the authors found

Table 2 - Distribution of parental guilt according to the children's age and caries severity.

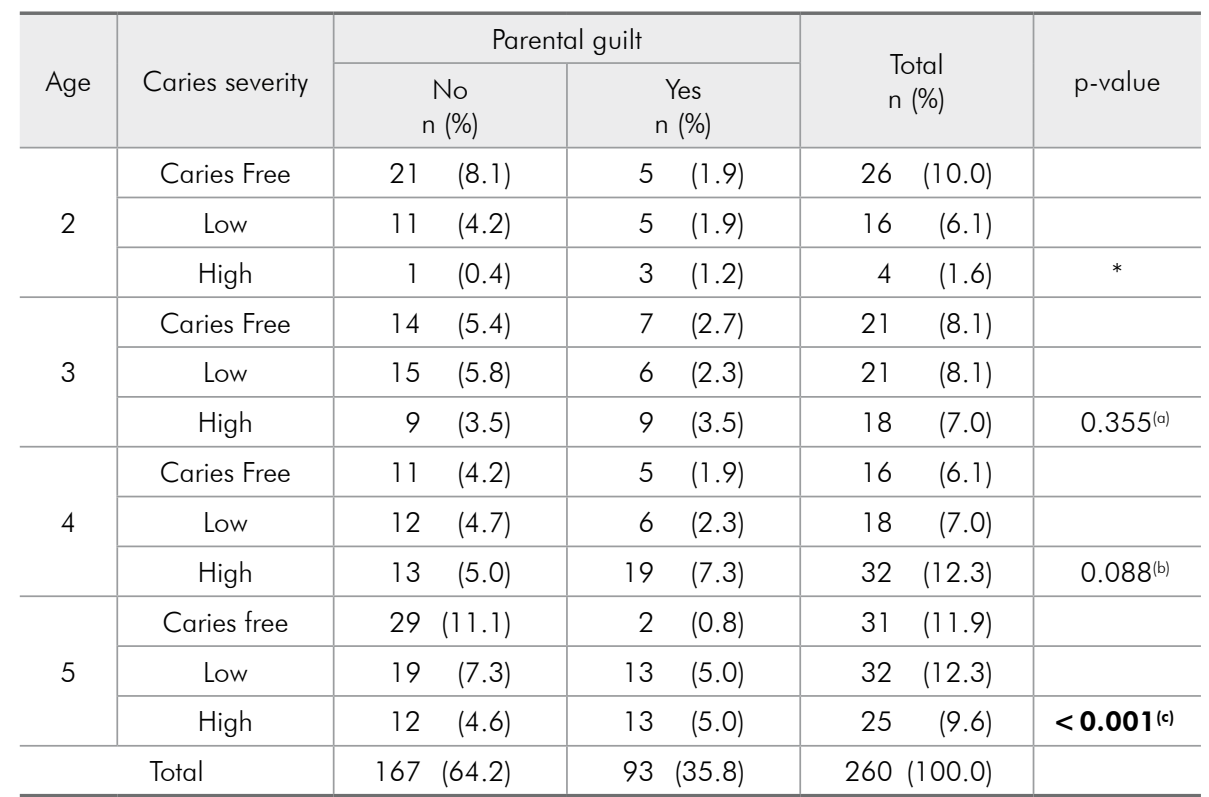

* Unable to adopt the Chi-square test; ${ }^{(a)} \chi^{2}=2.07 ; \mathrm{df}=2 ;{ }^{(b)} \chi^{2}=4.87 ; \mathrm{df}=2{ }^{\text {(c) }} \chi^{2}=15.03 ; \mathrm{df}=2$. 
Table 3 - Multivariate model of the association between the severity of caries and socioeconomic conditions.

\begin{tabular}{|c|c|c|c|}
\hline $\begin{array}{l}\text { Socioeconomic } \\
\text { conditions }\end{array}$ & n (\%) & Robust RR $(95 \% \mathrm{Cl})$ & $p$-value \\
\hline \multicolumn{4}{|c|}{ Child's age } \\
\hline 2 years old & $46(17.7)$ & & \\
\hline 3 years old & $60(23.1)$ & $2.05(1.17-3.61)$ & 0.012 \\
\hline 4 years old & $66(25.4)$ & $2.85(1.67-4.85)$ & $<0.001$ \\
\hline 5 years old & $88(33.8)$ & $2.16(1.23-3.72)$ & 0.006 \\
\hline \multicolumn{4}{|c|}{ Child's sex } \\
\hline Male & $137(52.7)$ & & \\
\hline Female & $123(47.3)$ & $0.74(0.56-0.98)$ & 0.035 \\
\hline Family income & $247(95.0)$ & $0.88(0.81-0.96)$ & 0.003 \\
\hline \multicolumn{4}{|c|}{ Mother's age } \\
\hline$\leq 30$ years & $121(46.7)$ & & \\
\hline$>30$ years & $138(53.3)$ & $0.71(0.54-0.94)$ & 0.018 \\
\hline \multicolumn{4}{|c|}{ Mother works away from home } \\
\hline No & $120(46.5)$ & & \\
\hline Yes & $138(53.5)$ & 0.75 (0.57-0.99) & 0.046 \\
\hline
\end{tabular}

* Wald test Chi-square: $p \leq 0.001$. Robust RR: Robust Rate Ratio.

that parents feared being blamed for their children's oral problems. Another study, which focused mainly on the quality of life of children with heart disease, observed that parents of special care children felt more guilty than parents of healthy children. ${ }^{20}$ This relationship between parental guilt and oral problems could be due to the impact that ECC has on the child, the family and the community. ${ }^{21}$

"Guilt" is a feeling that occurs when one assesses one's specific action as a failure or, especially, when the particular action has led to failure. ${ }^{22}$ The feeling of guilt is related to shame, which is felt when one considers oneself to be a "bad thing" because of what has happened. ${ }^{23}$ The present study considered all answers to be guilt, but did not investigate why parents felt guilty. However, the feeling of guilt arises when parents fear being blamed for their children's oral problems. ${ }^{11}$ This phenomenon can be speculated because the main causes of dental caries are widely broadcast by many oral health professionals. ${ }^{24}$ Therefore, if parents know how to prevent oral problems, it is reasonable to believe that their lack of preventive measures has led to their feelings of guilt.
Parental guilt could be further explained from another perspective. Parents commonly accept the lack of pain in their children to be a sign of good health. In addition, some parents believe that dental caries is a common/normal occurrence in children and that it is somehow inevitable. ${ }^{24}$ This misconception could explain the large number of parents who answered "never feeling guilty".

In the present study, parental guilt was assessed using one question from the ECOHIS questionnaire, but during its validation, ${ }^{25}$ a significant correlation was found between the section containing the question on guilt and the children's dental health $(\mathrm{r}=0.30)$. In our study, parental guilt and ECC showed a similar r-value, suggesting that this question could be used to measure parental guilt.

Although parental guilt was associated with dental caries, no association was found between parental guilt and socioeconomic factors, TDI or AMT. In relation to TDI, a condition which does not cause long periods of pain for the child, $84.6 \%$ of all TDI was categorised as "not severe". Similarly, AMT also causes no pain for the child. Therefore, parents might have judged their children as having no oral problems and not feel guilty for their children's TDI or AMT. Additionally, the factors associated with TDI and AMT are not clearly explained to parents. This can lead parents to believe that TDI is caused by accident or that AMT is hereditary. However, these oral problems can be prevented, ${ }^{9}$ and greater efforts should be made to educate parents and caretakers about the prevention of these problems. Therefore, one of the reasons for the significant increase in TDI during the last few years, from $9.4 \%$ to $13.9 \%$ in children, could be that parents and caretakers do not believe that TDI is preventable. ${ }^{3}$

As this study was performed during the Screening Programme, it is possible that parents would try to provide an answer simply to get their child into the dental treatment programme. However, as soon as the parents arrived, they were informed that the children would be placed on waiting lists and that treatment was guaranteed. As it was clear to the parents that all children would be admitted, there was little risk that the parents would provide answers that they perceived would enable their child to be 
admitted into treatment. Furthermore, parents usually seek dental care for their children when an oral problem arises. ${ }^{26}$ This phenomenon may explain the possible overestimation of the prevalence of ECC, TDI and AMT in our study, but there is also a possibility that these parents already felt guilty about their children's oral problems. This possibility could additionally indicate an overestimation in the presence of parental guilt. However, the present results show that parents are considerably more concerned about their children's oral health. ${ }^{27}$

Parental knowledge, attitudes and the family's socioeconomic condition have a direct influence on children's oral health; ${ }^{24,28}$ thus, it would be interesting to perform studies to discover the reasons for why parents feel guilty. Moreover, future studies should consider whether parents who feel guilty about their children's carious lesions could be motivated to change their behaviour towards better and

\section{References}

1. American Academy of Pediatric Dentistry. Definition of early childhood caries (ECC) [Internet]. Chicago: American Academy of Pediatric Dentistry; 2008 [cited 2012 May 12]. Available from: http://www.aapd.org/media/Policies_Guidelines/D_ ECC.pdf. 13 p.

2. Tiano AV, Moimaz SA, Saliba O, Garbin CA. Prevalence of enamel white spots and risk factors in children up to 36 months old. Braz Oral Res. 2009 Apr-Jun;23(2):215-22.

3. Cunha Bonini G, Marcenes W, Oliveira L, Sheiham A, Bönecker M. Trends in the prevalence of traumatic dental injuries in Brazilian preschool children. Dent Traumatol. 2009 Dec;25(6):594-8. Epub 2009 Sep 24.

4. Oliveira L, Marcenes W, Ardenghi T, Sheiham A, Bönecker M. Traumatic dental injuries and associated factors among Brazilian preschool children. Dent Traumatol 2007 Apr;23(2):76-81.

5. Robson F, Ramos-Jorge M, Bendo C, Vale M, Paiva S, Pordeus I. Prevalence and determining factors of traumatic injuries to primary teeth in preschool children. Dent Traumatol. 2009 Feb;25(1):118-22.

6. Heimer M, Tornisiello Katz C, Rosenblatt A. Non-nutritive sucking habits, dental malocclusions, and facial morphology in Brazilian children: a longitudinal study. Eur J Orthod. 2008 Dec;30(6):580-5.

7. Chevitarese A, Della Valle D, Moreira T. Prevalence of malocclusion in 4-6 year old Brazilian children. J Clin Pediatr Dent. $2002 ; 27(1): 81-5$. healthier habits. ${ }^{11,29}$ If such changes are possible, dentists can work with this issue to change oral habits in the family and improve oral health in preschool children.

\section{Conclusion}

In conclusion, it can be stated that the chances of parents feeling guilty for their children's oral problems increases with the increase of their children's dental caries severity; parental guilt is not associated with TDI or AMT.

\section{Acknowledgements}

We thank CAPES, CNPq and FAPESP for funding. We show our appreciation to Miname Araújo and Carolina Ramirez for their help in this study, and all who collaborated in the Screening Program. The authors emphatically express their gratitude to Marize Morais de Paiva for her exceptional efforts.

8. Innes N, Evans D. Managing dental caries in children: improving acceptability and outcomes through changing priorities and understanding the disease. Br Dent J. 2009 May;206(10):549-50.

9. Marcenes W, Alessi O, Traebert J. Causes and prevalence of traumatic injuries to the permanent incisors of school children aged 12 years in Jaragua do Sul, Brazil. Int Dent J. 2000 Apr;50(2):87-92.

10. Sexton S, Natale R. Risks and benefits of pacifiers. Am Fam Physician. 2009 Apr;79(8):681-5.

11. Amin M, Harrison R, Weinstein P. A qualitative look at parents' experience of their child's dental general anaesthesia. Int J Paediatr Dent. 2006 Sep;16(5):309-19.

12. Piovesan C, Mendes FM, Antunes JL, Ardenghi TM. Inequalities in the distribution of dental caries among 12-year-old Brazilian schoolchildren. Braz Oral Res. 20112011 JanFeb;25(1):69-75.

13. World Health Organization. Oral health surveys, basic methods. Geneva: World Health Organization; 1997.

14. Hallett K, O'Rourke P. Pattern and severity of early childhood caries. Community Dent Oral Epidemiol. 2006 Feb;34(1):25-35.

15. Glendor U, Marcenes W, Andreasen J. Classification, epidemiology and etiology. In: Andreasen JO, Andreasen FM, Andersson L, editors. Textbook and color atlas of traumatic injuries to the teeth. $4^{\text {th }}$ ed. Munksgaard: Blackwell Munksgaard; 2007. p. 217-54.

16. Aldrigui JM, Abanto J, Carvalho TS, Mendes FM, Wanderley MT, Boenecker M, et al. Impact of traumatic dental injuries 
and malocclusions on quality of life of young children. Health Qual Life Outcomes. 2011 Sep 24;9:78.

17. Abanto J, Carvalho TS, Mendes FM, Wanderley MT, Bönecker M, Raggio DP. Impact of oral diseases and disorders on oral health-related quality of life of preschool children. Community Dent Oral Epidemiol. 2011 Apr;39(2):105-14.

18. Jarman B. Identification of underprivileged areas. Br Med J (Clin Res Ed). 1983 May;286(6379):1705-9.

19. Martins-Júnior PA, Ramos-Jorge J, Paiva SM, Marques LS, Ramos-Jorge ML. Validations of the Brazilian version of the Early Childhood Oral Health Impact Scale (ECOHIS). Cad Saude Publica. 2012 Feb;28(2):367-74.

20. da Fonseca M, Evans M, Teske D, Thikkurissy S, Amini $H$. The impact of oral health on the quality of life of young patients with congenital cardiac disease. Cardiol Young. 2009 Jun;19(3):252-6.

21. Casamassimo P, Thikkurissy S, Edelstein B, Maiorini E. Beyond the dmft: the human and economic cost of early childhood caries. J Am Dent Assoc. 2009 Jun;140(6):650-7.

22. Lewis M, Haviland-Jones JM, Barret LF. Handbook of emotions. $3^{\text {rd }}$ ed. New York: The Guilford Press; 2008.
23. Tangney JP, Wagner P, Gramzow R. Proneness to shame, proneness to guilt, and psychopathology. J Abnorm Psychol. 1992 Aug;101(3):469-78.

24. Amin M, Harrison R. Understanding parents' oral health behaviors for their young children. Qual Health Res. 2009 Jan;19(1):116-27.

25. Pahel B, Rozier R, Slade G. Parental perceptions of children's oral health: the Early Childhood Oral Health Impact Scale (ECOHIS). Health Qual Life Outcomes. 2007 Jan 30;5:6.

26. Nuttall N, Steele J, Pine C, White D, Pitts N. The impact of oral health on people in the UK in 1998. Br Dent J. 2001 Feb;190(3):121-6.

27. Nainar S, Crall J. Caries experience in inner-city preschoolers at the time of their initial dental visit. ASDC J Dent Child. 1997;64(6):421-4.

28. Wong D, Perez-Spiess S, Julliard K. Attitudes of Chinese parents toward the oral health of their children with caries: a qualitative study. Pediatr Dent. 2005;27(6):505-12.

29. Weinstein P. Behavioral problems in the utilization of new technology to control caries: patients and provider readiness and motivation. BMC Oral Health. 2006;6 Suppl 1:S5. 